\title{
Comparison of Insertion Time, Pull-out Strength, and Screw-media Interface Area of Customized Pedicle Screw With Different Core and Thread Design Against Commercial Pedicle Screw
}

\section{Rahadyan Magetsari ( $\nabla$ rahadyan@ugm.ac.id)}

Gadjah Mada University Faculty of Medicine, Public Health, and Nursing: Universitas Gadjah Mada Fakultas Kedokteran Kesehatan Masyarakat dan Keperawatan https://orcid.org/0000-0002-7887-8310 Tedjo Rukmoyo

Gadjah Mada University Faculty of Medicine, Public Health, and Nursing: Universitas Gadjah Mada Fakultas Kedokteran Kesehatan Masyarakat dan Keperawatan

\section{Marda Ade Saputra}

Gadjah Mada University Faculty of Medicine, Public Health, and Nursing: Universitas Gadjah Mada Fakultas Kedokteran Kesehatan Masyarakat dan Keperawatan

\section{Yudha Mathan Sakti}

Gadjah Mada University Faculty of Medicine, Public Health, and Nursing: Universitas Gadjah Mada Fakultas Kedokteran Kesehatan Masyarakat dan Keperawatan

\section{Research note}

Keywords: pedicle screw, pull-out strength, insertion time, interface area

Posted Date: April 20th, 2021

DOl: https://doi.org/10.21203/rs.3.rs-429747/v1

License: (c) (i) This work is licensed under a Creative Commons Attribution 4.0 International License. Read Full License 


\section{Abstract}

Objective: This research aimed to developing customized pedicle screw based on Indonesian vertebral anatomy and compare the insertion time, pull-out strength, and screw-media interface area of different screw design. We have developed 3 different types of pedicle screws ( $v$-thread cylinder-core, squarethread cylinder-core and square-thread conical-core). The thread diameter was calculated from pedicle width of Indonesian population $(6 \mathrm{~mm})$. We used commercially available pedicle screw as control group (6.2 mm).

Result: The insertion time were significantly difference between v-thread cylinder-core pedicle screw $(22,94 \mathrm{~s})$ with commercially available pedicle screw $(15.86 \mathrm{~s})(\mathrm{p}<0.05)$. The pull-out strength was significantly difference between commercially available pedicle screw $(408.60 \mathrm{~N})$ with square-thread conical pedicle screw $(836.60 \mathrm{~N})(\mathrm{p}<0.05)$. The square-thread conical-core group have the highest interface area $\left(1486.21 \mathrm{~mm}^{2}\right)$. The data comparison showed that the square-thread conical-core customized pedicle screw group has comparable insertion time and has better pull-out strength than commercially available pedicle screw.

\section{Introduction}

Pedicle screw is widely used in spinal surgeries. It is as a gold standard for fusion procedure of spine. The example uses of pedicle screw are in correcting scoliosis deformity, disc degenerative disease, infection in spine, tumor, and fractures ${ }^{1}$.

In Indonesia, the use of pedicle screw is still limited due to its cost and complexity in its instruments for application. There is no single factory in Indonesia that has been able to produce pedicle screw. The needs for pedicle screws are all being full filled by importing from aboard.

Although pedicle screw has the advantage as one of the most rigid fixator ${ }^{2}$, failure of fixation is still can occur. Factor that can be one of potential risk for failure of fixation is pull-out strength of pedicle screw. Some studies have reported that different design of thread and core of pedicle screw affect its biomechanical properties like insertion time and pull-out strength ${ }^{3,4,5}$. Size of the screw is also important, with bigger size and larger surface area correlates with greater pull-out strength, but it is also limited by the size of the anatomical size of the pedicle. Study of anatomical size of pedicle in Indonesian population that had been held by Wibowo and Suwardi in 2017, found that it has smaller size compare to western population where commercially available pedicle screws are being produced ${ }^{6,7}$. In this case, the challenge is to produce pedicle screws with specific size based on Indonesian pedicle anatomy and designs that have comparable insertion time and pull-out strength to commercially available pedicle screws.

The aim of this study was to develop a customized pedicle screw based on Indonesian vertebral anatomy and compare the insertion time, pull-out strength, and screw-media interface area of different screw 
design.

\section{Material And Methods}

This was an experimental study. We used 4 groups of pedicle screws with 5 screws each, that consist of group A (v-thread cylinder-core pedicle screw), group B (square-thread conical-core pedicle screw), group $C$ (square-thread cylinder-core pedicle screw), and group D (commercially available pedicle screw). We used $6 \mathrm{~mm}$ of diameter for our customized pedicle screw based on study of thoracic and lumbar pedicle of Indonesian population instead of $6.2 \mathrm{~mm}$ of diameter of commercially available pedicle screw. Our pedicle screws were made of AISI 316 L and being produced at UPT Logam in Yogyakarta city of Indonesia by using Computerized Numerical Control (CNC) machines. The human resources consist of orthopaedic surgeon, resident and technician team. Statistical calculations were carried out with the IBM SPSS Statistics ver. 22.0 (IBM Co., Armonk, NY, USA).

We performed insertion time test, pull-out strength test and measurement of screw-media interface area for all groups of pedicle screws. The tests were being performed at laboratory of mechanical engineering faculty of Universitas Gadjah Mada.

\section{Result}

We evaluated 4 groups of pedicle screws that consist of 15 customized pedicle screws and 5 commercially available pedicle screws. Presented in Table 1., the mean of insertion time for group A was 22.94 seconds, 17.04 seconds for group $B, 15.57$ seconds for group $C$, and 15.86 seconds for group $D$. The mean of pull-out strength for group A was 746.6 Newton, 836.6 Newton for group B, 692.4 Newton for group $C$, and 408.6 Newton for group $D$. The measurement of screw-media interface area of group $A$ was $1147.93 \mathrm{~mm}^{2}, 1486.21 \mathrm{~mm}^{2}$ for group $\mathrm{B}, 1473.33 \mathrm{~mm}^{2}$ for group $\mathrm{C}$, and $1054.63 \mathrm{~mm}^{2}$ for group D.

Table 1. Means of insertion time and pull-out strength 


\begin{tabular}{|c|c|c|c|c|c|}
\hline \multicolumn{6}{|l|}{ Descriptive Result } \\
\hline & & $\mathrm{N}$ & Minimum & Maximum & Mean $\pm S D$ \\
\hline \multirow[t]{5}{*}{ Insertion time (second) } & V cylinder $(\mathrm{A})$ & 5 & 19.97 & 28.85 & $22.94 \pm 1.54$ \\
\hline & Square conical (B) & 5 & 15.79 & 18.88 & $17.04 \pm 0.64$ \\
\hline & Square cylinder (C) & 5 & 10.85 & 19.27 & $15.57 \pm 1.56$ \\
\hline & Commercial (D) & 5 & 9.19 & 22.72 & $15.86 \pm 2.44$ \\
\hline & Total & 20 & 9.19 & 28.85 & $17.85 \pm 1.02$ \\
\hline \multirow[t]{5}{*}{ Pullout strength (Newton) } & V cylinder $(A)$ & 5 & 476 & 1043 & $746.60 \pm 97.89$ \\
\hline & Square conical (B) & 5 & 618 & 1143 & $836.60 \pm 95.05$ \\
\hline & Square cylinder (C) & 5 & 579 & 860 & $692.40 \pm 48.54$ \\
\hline & Commercial (D) & 5 & 314 & 541 & $408.60 \pm 43.23$ \\
\hline & Total & 20 & 314 & 1143 & $671.05 \pm 50.50$ \\
\hline
\end{tabular}

The results of insertion time test show that group B pedicle screw with square-thread conical-core design has moderate insertion time compare to other pedicle screw groups. The results of pull-out strength test show that group B pedicle screw has the highest pull-out strength compare to other pedicle screws and it is also correlated with the measurement of screw-media interface area which show that group $B$ has the largest results.

Based on Table 2. it is showed that the insertion time of customized pedicle screws were not statistically different compare to commercially available pedicle screw except for v-thread cylinder-core group which showed the slowest insertion time. It is also showed that the pull-out strength of group B pedicle screw was significantly higher than commercially available pedicle screw.

Table 2. Statistical analysis of insertion time 


\begin{tabular}{|c|c|c|c|c|c|}
\hline Dependent & \multicolumn{2}{|c|}{ Screw Type } & Mean & $\mathrm{p}$ Value & $95 \% \mathrm{Cl}$ \\
\hline \multirow{12}{*}{$\begin{array}{l}\text { Insertion } \\
\text { Time }\end{array}$} & \multirow{3}{*}{ V Cylinder (A) } & Square Conical (B) & $5,90 \pm 2.36$ & 0,10 & $-0,87-12,67$ \\
\hline & & Square Cylinder (C) & $7,37^{*} \pm 2.36$ & 0,03 & $0,56-14,13$ \\
\hline & & Commercial (D) & $7,09^{*} \pm 2.36$ & 0,04 & $0,31-13,86$ \\
\hline & \multirow{3}{*}{ Square Conical (B) } & V Cylinder (A) & $-5,90 \pm 2.36$ & 0,10 & $-12,67-0,87$ \\
\hline & & Square Cylinder (C) & $1,47 \pm 2.36$ & 0,92 & $-5,30-8,24$ \\
\hline & & Commercial (D) & $1,20 \pm 2.36$ & 0,95 & $-5,60-7,96$ \\
\hline & \multirow{3}{*}{$\begin{array}{l}\text { Square Cylinder } \\
\text { (C) }\end{array}$} & V Cylinder (A) & $-7,37^{*} \pm 2.36$ & 0,03 & $-14,13-0,60$ \\
\hline & & Square Conical (B) & $-1,47 \pm 2.36$ & 0,92 & $-8,24-5,30$ \\
\hline & & Commercial (D) & $-2,82 \pm 2.36$ & 0,99 & $-7,05-6,50$ \\
\hline & \multirow{3}{*}{ Commercial (D) } & V Cylinder (A) & $-7,09^{*} \pm 2.36$ & 0,04 & $-13,85-0,31$ \\
\hline & & Square Conical (B) & $-1,19 \pm 2.36$ & 0,96 & $-7,96-5,60$ \\
\hline & & Square Cylinder (C) & $0,28 \pm 2.36$ & 0,99 & $-6,50-7,05$ \\
\hline \multirow{12}{*}{$\begin{array}{l}\text { Pull-out } \\
\text { Strength }\end{array}$} & \multirow{3}{*}{ V Cylinder (A) } & Square Conical (B) & $-90,00 \pm 106.87$ & 0,834 & $-395,76-215,76$ \\
\hline & & Square Cylinder (C) & $54,20 \pm 106.87$ & 0,956 & $-251,56-359,96$ \\
\hline & & Commercial (D) & $338,00^{\circ} \pm 106.87$ & 0,028 & $32,24-643,76$ \\
\hline & \multirow{3}{*}{ Square Conical (B) } & V Cylinder (A) & $90,00 \pm 106.87$ & 0,834 & $-215,76-395,76$ \\
\hline & & Square Cylinder (C) & $144,20 \pm 106.87$ & 0,547 & $-161,56-449,96$ \\
\hline & & Commercial (D) & $428,00^{\circ} \pm 106.87$ & 0,005 & $122,24-733,76$ \\
\hline & \multirow{3}{*}{$\begin{array}{l}\text { Square Cylinder } \\
\text { (C) }\end{array}$} & V Cylinder (A) & $-54,20 \pm 106.87$ & 0,956 & $-359,96-251,56$ \\
\hline & & Square Conical (B) & $144,20 \pm 106.87$ & 0,547 & $-449,96-161,56$ \\
\hline & & Commercial (D) & $283,80 \pm 106.87$ & 0,074 & $-21,96-589,56$ \\
\hline & \multirow{3}{*}{ Commercial (D) } & V Cylinder (A) & $\begin{array}{c}- \\
338.00^{\circ} \pm 106.87\end{array}$ & 0,028 & $-643,76-32,24$ \\
\hline & & Square Conical (B) & $\begin{array}{c}- \\
428.00^{*} \pm 106.87\end{array}$ & 0,005 & $-733,76-122,24$ \\
\hline & & Square Cylinder (C) & $-283.80 \pm 106.87$ & 0,074 & $-589,56-21,96$ \\
\hline
\end{tabular}

\section{Discussion}

This study found that the insertion time were significantly difference between v-thread cylinder-core pedicle screw $(22,94 s)$ with commercially available pedicle screw $(15,86 s)(p<0,05)$. The pull-out strength was significantly difference between commercially available pedicle screw $(408,60 \mathrm{~N})$ with square-thread conical pedicle screw $(836,60 \mathrm{~N})(\mathrm{p}<0,05)$. The square-thread conical-core group have the highest interface area $\left(1486,21 \mathrm{~mm}^{2}\right)$. 
The insertion time of pedicle screw is important because it can be a factor that influence how fast a surgeon can finish the operation. The longer the time taken to insert a pedicle screw means the longer the duration of surgery and the higher the risk of complications. Cheng Hang had reported that every additional of 15 minutes for surgery times can increase the infection rate by $13 \%{ }^{8}$

Study by Higashino $\mathrm{K}$ showed that pedicle screw removal was found to be 435.6 Newton in osteoporotic vertebra, ${ }^{9}$ which is comparable to this study for measurement of commercially available pedicle screw group (408.6 Newton). This study propose that best combination of pedicle screw design is square-thread conical-core design regarding the statistical analysis due to its comparable insertion time and higher pullout strength compare to commercially available pedicle screw.

Screw loosening was found between $0.6-11 \%$ and might be higher in osteoporotic bone. Re operation rate because pedicle screw loosening was found between $14-27 \% .{ }^{10}$ Fixation failure because of screw loosening might change the spinal alignment and fixation stability that might harm the patient.

The geometry of the pedicle screw core can be conical, cylindrical or combination of both. The three types have different mechanical strengths. Abshire et al. Compared the conical and cylindrical core designs and concluded that the conical screw has a better pull-out strength than the core cylinder. ${ }^{3}$ However, Kwok et al carried out a similar study and found that there was no significant difference in the pull-out strength between screw with conical design and cylinder core. ${ }^{11}$ Meanwhile, Yaman et al examined the pull-out strength of a pedicle screw with dual core and found that the design had a higher pull-out strength value compared to the screw with conical and cylinder cores. ${ }^{1}$ The limitation in this study is that we cannot use a pedicle screw with dual cores due to the limited production equipment.

Kim et al examined the shape of the thread on a screw and its effect on pull-out strength and found that threads with a v-thread design had a higher pull-out strength compared to square threads. According to their study, this is influenced by the flank overlap area (FOA) and thread pitch where the screw which has a larger flank overlap area and a smaller thread pitch has a higher pull-out strength value. ${ }^{4}$ This is different from the results we obtained in this study where the pull-out strength value of a pedicle screw with a square thread has a higher pull-out strength value than a pedicle screw with a v-thread. This may be influenced by the contact surface area between the screw and the larger media on the pedicle screw with the square thread which in this study was successfully measured using the solid works software program. This difference certainly requires further study and further research with a larger sample size may be required.

\section{Conclusion}

This study showed that our institution has been able to develop customized pedicle screws that the square-thread conical-core customized pedicle screw group has comparable insertion time and has better pull-out strength than commercially available pedicle screw. 


\section{Limitation}

Our recent development of pedicle screw has only designed for lumbar segment of vertebra. Further research is mandatory to develop another pedicle screw for thoracal and cervical segment. We propose the continuation of this research by comparing designed pedicle screw of lumbar, thoracal and cervical segment.

\section{Declarations}

\section{Ethical clearance}

Ethical clearance in this study is not applicable as it didn't involve human data, human tissue, or animal.

\section{Consent for publication}

Consent for publication is not applicable.

\section{Avaibility of data and material}

This study doesn't contain any individual data. The datasets used and/or analysed during the current study are available from the corresponding author on reasonable request. The data is available on this manuscript.

\section{Funding}

The authors declare that this study had no external funding resource. The authors declare that they have no competing interests.

\section{Author's Contribution}

Rahadyan Magetsari conceived the study. Tedjo Rukmoyo, Marda Ade Saputra and Yudha Mathan Sakti, drafted the manuscript and critically revised the manuscript by Rahadyan Magetasari for important intellectual content. Tedjo Rukmoyo, Marda Ade Saputra and Yudha Mathan Sakti facilitated all projectrelated tasks.

\section{Acknowledgements}

We thank patient family, the surgical team and the nursing staff who were involved in the surgery and patients care. 


\section{References}

1. Onur Yaman. The Comparison of Pull-out Strengths of Various Pedicle Screw Designs on Synthetic Foams and Ovine Vertebrae Turk Neurosurg 2015, Vol: 25, No: 4, 532-538

2. Ching-Chi Hsu a, Ching-Kong Chao a, Increase of pull-out strength of spinal pedicle screws with conical core: biomechanical tests and finite element analyses Journal of Orthopaedic Research 23 (2005) 788-794

3. Abshire BB, McLain RF, Valdevit A, Kambic HE (2001) Characteristics of pull-out failure in conical and cylindrical pedicle screws after full insertion and back out. Spine J 1:408-414

4. Kim YY, Choi WS, Rhyu KW (2012) Assessment of pedicle screw pull-out strength based on various screw designs and bone densities. Spine J 12:164-168

5. Lin J, Lin SJ, Chiang H, Hou SM. Bending strength and holding power of tibia1 locking screws. Clin Orthop 2001;385:199-206.

6. Wibowo ES. 2016. Morfometri Tiga Dimensi Vertebra Torakal pada Populasi Indonesia. UGM : Yogyakarta

7. Suwardi T. 2017. Morfometri Tiga Dimensi Vertebra Lumbar pada Populasi Indonesia. UGM : Yogyakarta

8. Hang Cheng, Brian Po-Han Chen, Ireena M. Soleas, Nicole C. Ferko, Chris G. Cameron, and Piet Hinoul1Prolonged Operative Duration Increases Risk of Surgical Site Infections: A Systematic Review Surgical Infections Volume 18, Number 6, 2017

9. K. Higashino, J. Kim, W.C. Horton W.C. Hutton. Biomechanical study of two different pedicle screw fixation methods when used in osteoporotic and non-osteoporotic vertebrae *Atlanta Veterans Affairs Medical Center and the Department of Orthopedic Surgery, Emory University School of Medicine, Atlanta, USA 2010 Mary Ann Liebert, Inc. DOI: 10.1089/sur.2017.089

10. Okuyama K, Abe E, Suzuki T, Tamura Y, Chiba M, Sat0 K. Can insertion torque predict screw loosening and related failures? An in vivo study of pedicle screw fixation augmenting posterior lumbar interbody fusion. Spine 200025:85844.

11. Kwok AW, Finkelstein JA, Woodside T, Hearn TC, Hu RW (1996) Insertional torque and pull-out strengths of conical and cylindrical pedicle screws in cadaveric bone. Spine (PhilaPa 1976) 21(21):2429-2434.

\section{Figures}



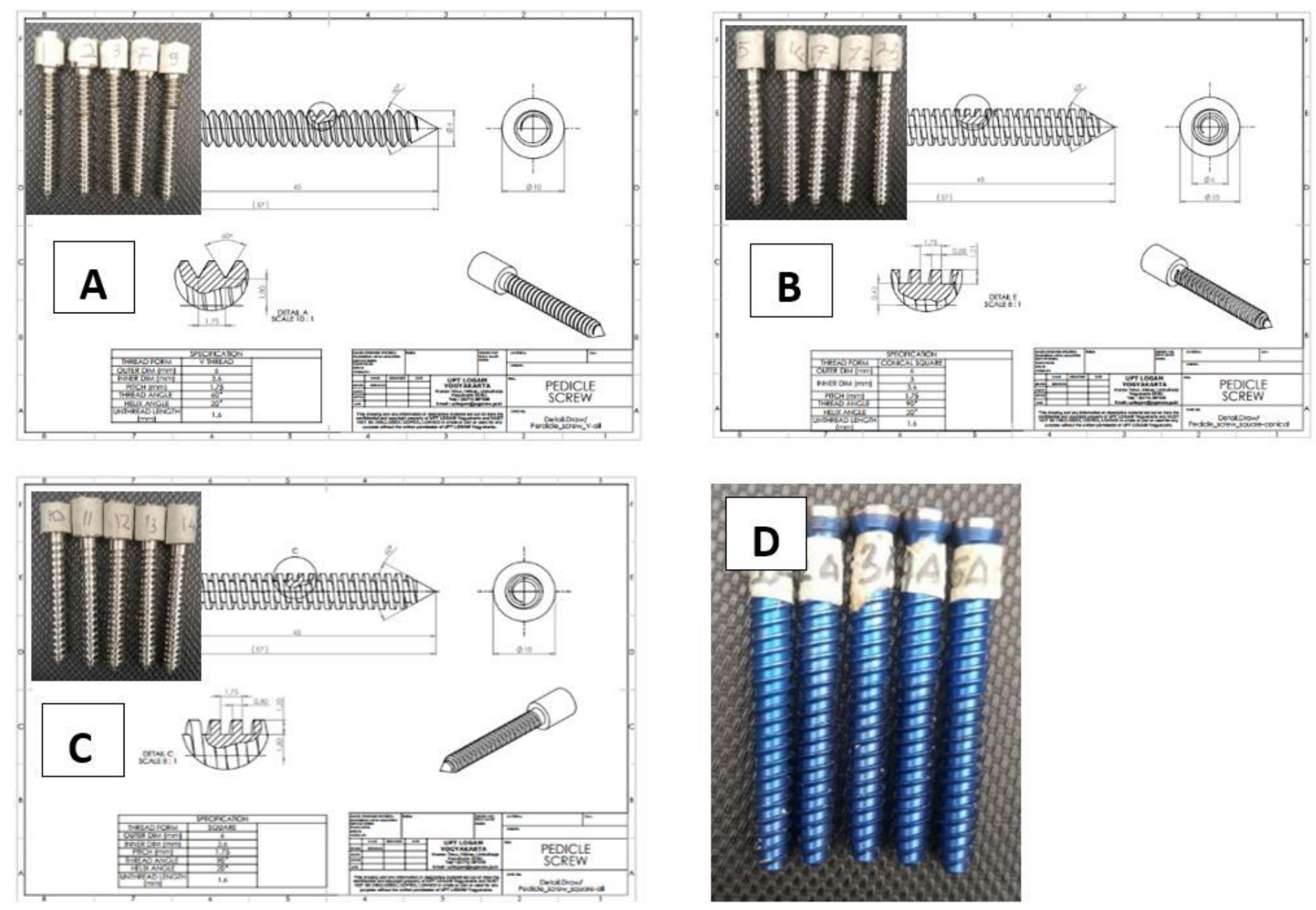

Figure 1

Design and final result of customized screw; (A) Cylinder core, (B) Square-thread cylinder-core and (C) Square-thread conical-core and commercially available pedicle screw (D) EXPEDIUM ${ }^{\circledR}$ 5,5 Spine System pedicle screw (DePuy Synthes, United States, California) 